\title{
Effect of omeprazole, rabeprazole, and rebamipide on the accuracy of urea breath test in patients with Helicobacter pylori infection
}

\author{
Duangporn Thong-Ngam ${ }^{\mathrm{a}}$, Maneerat Chayanupatkul ${ }^{\mathrm{a}}$, Thirada Thongbai ${ }^{\mathrm{b}}$ \\ ${ }^{a}$ Department of Physiology, ${ }^{b}$ Gastroenterology Unit, Department of Medicine, Faculty of Medicine, \\ Chulalongkorn University, Bangkok 10330, Thailand
}

\begin{abstract}
Background: The urea breath test (UBT) has been widely used for H. pylori eradication after treatment. The breath test could be adversely affected by various factors including proton pump inhibitors (PPIs) that are also used in the therapy for $H$. pylori infection.

Objective: Determine the effect of omeprazole, rabeprazole and the mucoprotective agent rebamipide, on the UBT. Methods: Fifty-six patients with dyspepsia and positive for $H$. pylori by rapid urease test were enrolled. They were classified into three groups: Group $1(n=25)$ received omeprazole $20 \mathrm{mg}$ once daily, group $2(\mathrm{n}=13)$ received rabeprazole $20 \mathrm{mg}$ once daily, and group $3(\mathrm{n}=18)$ received rebamipide $100 \mathrm{mg}$ three times a day. All patients received a 14-day course of their medications. UBT was performed on day 0 as a baseline and on day 14 in all patients. In patient with negative results of UBT on day 14, the UBT was performed in consecutive week until the test became positive.

Results: Fifty-six patients (20 men and 36 women) participated in the study. Their mean age was $46.77 \pm 14.3$ years. False negative rate after 14-day treatment in omeprazole, rabeprazole and rebamipide group were $20.0 \%, 30.8 \%$, and $0 \%$ respectively. There was a significant difference between ${ }^{13} \mathrm{C}$ level in patients with negative and positive UBT results $(2.7 \pm 0.7 v s .22 .9 \pm 3.7 / \mathrm{mL}, \mathrm{p}=0.025)$. The reversal of false negative to true positive tests occurred within two weeks after discontinuation of omeprazole and rabeprazole.

Conclusion: Proton pump inhibitors had an effect on the accuracy of H. pylori detection using UBT. Rabeprazole revealed a higher false negative rate in the UBT than omeprazole. The mucoprotective drug, rebamipide, did not influence negative results in the UBT.
\end{abstract}

Keywords: Helicobacter pylori, rabeprazole, rebamipide, urea breath test.

Helicobacter pylori infection is now considered the most common cause of peptic ulcer disease. It has been implicated as a major factor in the pathogenesis of gastric adenocarcinoma and lowgrade gastric lymphoma of mucosa-associated lymphoid tissue (MALT) [1-3]. The detection of $H$. pylori can be done using several diagnostic tests. They include invasive tests, such as biopsy urease test, histology and culture, and non-invasive tests, such as serology, urea breath test and stool antigen test. These tests vary in sensitivity and specificity. The most

Correspondence to: Thong-Ngam D, MD, Department of Physiology, Faculty of Medicine, Chulalongkorn University, Bangkok 10330, Thailand.E-mail:thongngam007@yahoo.com commonly used diagnostic test in clinical practice in Thailand is the rapid urease test accomplished by mucosal biopsy during endoscopy with sensitivity of $88-95 \%$ and specificity of $95-100 \%$ [3]. The urea breath test (UBT) is also recommended for determination of success of $H$. pylori eradication.

H. pylori causes urease splitting, which is uncommon in other important bacteria. Since the normal human stomach is devoid of urease, the detection of gastric urease is indicative of active $H$. pylori infection $[3,4]$. Two UBTs are now approved by the US-FDA. One is a ${ }^{13} \mathrm{C}$ based test and the other is a ${ }^{14} \mathrm{C}$ based test. The both types of UBT are quite similar in sensitivity (90-96\%) and specificity (8898\%) [3-15]. Despite its high accuracy, many factors 
have been implicated to cause false negative UBT including proton pump inhibitors (PPIs), $\mathrm{H}_{2}$ receptor antagonist, bismuth, and antibiotics.

PPIs have been widely used to manage acidrelated disorders for the last decade. These agents selectively and irreversibly block the gastric hydrogen/potassium adenosine triphosphatase $\left(\mathrm{H}^{+} / \mathrm{K}^{+}\right.$ATPase), a final step in acid secretion $[5,6]$. They inhibit acid secretion independently of the state of parietal cell stimulation. PPIs are effective against gastroesophageal reflux disease (GERD), peptic ulcer, Barrett's esophagus, Zollinger-Ellison syndrome. It is also a part of combination therapy for $H$. pylori eradication $[5,6]$. PPIs comprise many agents that differ slightly in pharmacokinetics, potency, acid suppression, clinical efficacy, cost, and toxicity [5].

Previous studies have shown that taking PPIs could lead to false negative UBT with false negative rate. It ranges from $2.3 \%$ to $38.0 \%$ [7-11]. There were few studies regarding false negative rates with rabeprazole.

There are several hypotheses to explain the cause of false negative UBT tests. One concerns the effect of PPIs on intragastric $\mathrm{pH}$ by making the intragastric environment undesirable for $H$. pylori, leading to a fall in the bacterial load [12]. The rise in gastric $\mathrm{pH}$ caused by PPIs may reduce the utilization of urea into H. pylori, and thus bacterial urease activity [11]. PPIs also have a direct bactericidal effect against H. pylori, which in turn reduces the bacteria load [12-14]. In spite of abundant evidence supporting the adverse effect of PPIs on the sensitivity of UBT, it is still unclear whether rebamipide, a mucoprotective agent, could influence the accuracy of UBT. In the present study, we investigated the effect of omeprazole, rabeprazole, and rebamipide on the accuracy of the urea breath test.

\section{Materials and methods \\ Subject}

Fifty-six patients (20 men and 36 women) with dyspepsia attending the outpatient clinic at King Chulalongkorn Memorial Hospital were recruited in the study between January 2006 and December 2006. All patients enrolled in this study had undergone endoscopies with one biopsy at the antrum for the rapid urease test (CLO test ${ }^{\circledR}$, Utah, USA), which had been read as $H$. pylori positive by changing from yellow to pink within 24 hours. Exclusion criteria consisted of previous gastric surgery, pregnancy, current breast feeding, gastric ulcer, duodenal ulcer, gastric cancer or known allergy to medications used in this study. The study was approved by the Ethics Committee of the Faculty of Medicine, Chulalongkorn University. Written informed consent was obtained from each patient prior to participation.

\section{Study design}

Fifty-six patients were randomly classified into three groups: omeprazole, rabeprazole, and rebamipide group. They were administered omeprazole $20 \mathrm{mg} /$ day, rabeprazole $20 \mathrm{mg} /$ day and rebamipide $300 \mathrm{mg} /$ day, respectively. The UBT was performed twice, before starting medication and after 14-days of treatment. Patients in the omeprazole group were examined using ${ }^{13} \mathrm{C}$ UBT, while the other two groups were tested using ${ }^{14} \mathrm{C}$ UBT due to the availability of these tests. Breath tests were performed weekly after cessation of medication in patients with negative results of UBT on day 14 until the test became positive.

\section{Urea breath test}

Patients were requested not to take any medications that could influence the UBT results and come after an overnight fast. ${ }^{13} \mathrm{C}$ UBT (Otsuka Pharmaceutical, Tokyo, Japan) was performed using molecular correlation spectroscopy (Continuous Real Time Breath ID System, Oridion, Jerusalem, Israel). After obtaining baseline breath samples, patients were requested to drink a solution of ${ }^{13} \mathrm{C}$ urea $100 \mathrm{mg}$ (Campo Scientific, Veenendaal, The Netherlands) in $50 \mathrm{~mL}$ of water. The second breath sample was taken 30 minutes later. The Breath ID continuously measures ${ }^{13} \mathrm{CO}_{2}$ and ${ }^{12} \mathrm{CO}_{2}$ concentrations from breath samples. We calculated the ratio of ${ }^{13} \mathrm{CO}_{2}$ to ${ }^{12} \mathrm{CO}_{2}$. The cutoff point for the Breath ID test has been determined to be four "delta over baseline" (DOB). A test result with DOB of equal (or greater than four) was defined as positive, whereas the final reading of DOB less than four was interpreted as negative.

${ }^{14} \mathrm{C}$ UBT was performed using PYtest kit with a microcount liquid scintillation counter (Kimberly-Clark/ Ballard Medical Products, Roswell, USA). Six hours after fasting and two hours without smoking tobacco products, patients swallowed the capsule containing $1 \mu \mathrm{Ci}$ of ${ }^{14} \mathrm{C}$ urea with $20 \mathrm{~mL}$ of lukewarm water, followed by an additional $20 \mathrm{~mL}$ of water three minutes later. At ten minutes post-dose, the patient was requested to take a deep breath, hold it for 3-10 seconds, and exhale through a straw into a mylar 
breath collection balloon. Then, the air from the balloon was transferred into a scintillation vial containing hyamine, methanol and thymolphthalein. The patient continued breathing through to the system until discoloration occurred, indicating the adequacy of breath sample collection. Then, $10 \mathrm{~mL}$ scintillation fluid was added to each vial. The breath sample was analyzed for the presence of ${ }^{14} \mathrm{C}$ with a liquid scintillation counter. The quantification was reported as disintegrations per minute (DPM). DPM less than 50 was considered negative, while DPM equal or greater than 200 was determined as positive.

\section{Statistical analysis}

Continuous data were expressed as mean $\pm \mathrm{SEM}$. Chi-square or Fisher's exact test was used to compare the demographic characteristics and the number of false negative UBT among groups. Data processing was accomplished using SPSS software for windows (version 16, SPSS, Chicago, USA). All tests were considered significant at $\mathrm{p}<0.05$.

\section{Results}

Fifty-six patients (20 men and 36 women) participated in the study with a mean age of $46.8 \pm 14.3$ years (range: 19-79 years). Patients enrolled in this study were classified into three groups. Twenty-five patients (8 men and 17 women) in the omeprazole group had average age of $46.0 \pm 2.8$ years. The rabeprazole group was comprised of 13 patients (six men and seven women) with a mean age of $49.1 \pm 4.7$ years. Another 18 patients (6 men and 12 women) were the rebamipide group with an average age of
$46.2 \pm 3.1$ years. There was no significant difference in the number of cases, ages and gender among groups. All demographic data in each group are shown in Table 1.

All patients with positive rapid urease test were confirmed to be positive by UBT on day 0 . The $5 / 25$ in the omeprazole group, $4 / 13$ in the rabeprazole group and 0/18 in the rebamipide group had negative UBTs 14 days after treatment. These were considered as false negative because antibiotics for $H$. pylori eradication had not been prescribed. As shown in Table 1, percentage of false negative results in omeprazole, rabeprazole and rebamipide group were $20 \%, 30.8 \%$, and $0 \%$, respectively. The false negative rate in the rabeprazole group differed significantly from rebamipide group $(\mathrm{p}=0.023)$. Therefore, there was no significant difference in the false negative rate between rebamipide and omeprazole groups or between omeprazole and the rabeprazole group.

In the omeprazole group, the ${ }^{13} \mathrm{C}$ level at baseline (mean \pm SEM: $25.52 \pm 3.29 / \mathrm{mL}$ ) was higher than the ${ }^{13} \mathrm{C}$ level 14 days after treatment (mean= 18.77 \pm 3.38 ) without statistical significance. The ${ }^{13} \mathrm{C}$ level in patients with negative results (mean \pm SEM: $2.68 \pm 0.7 / \mathrm{mL}$ ) was found to be significantly lower than in those with positive tests (mean \pm SEM: $22.86 \pm 3.7$ $\mathrm{mL}$ ), $\mathrm{p}=0.025$ ) (Fig. 1). The ${ }^{13} \mathrm{C}$ level in omeprazole group did not seem to be influenced by sex, alcohol and smoking.

All patients with false negative results regained a positive test two weeks after drug cessation. No serious adverse effects were reported in all three groups.

Table1. Demographic data and UBT test results in omeprazole, rabeprazole and rebamipide group.

\begin{tabular}{|c|c|c|c|c|}
\hline Variables & & Omeprazole & Rabeprazole & Rebamipide \\
\hline Number of cases & & 25 & 13 & 28 \\
\hline Age (years) & & $46.0 \pm 2.8$ & $49.1 \pm 4.7$ & $46.2 \pm 3.1$ \\
\hline $\begin{array}{l}\text { Gender } \\
\text { (number, percent) }\end{array}$ & $\begin{array}{l}\text { Female } \\
\text { Male }\end{array}$ & $\begin{array}{l}17(68 \%) \\
8(32 \%)\end{array}$ & $\begin{array}{l}7(54 \%) \\
6(46 \%)\end{array}$ & $\begin{array}{c}12(67 \%) \\
6(33 \%)\end{array}$ \\
\hline $\begin{array}{l}\text { UBT result on day } 14 \\
\text { (number, percent) }\end{array}$ & $\begin{array}{l}\text { Positive } \\
\text { Negative }\end{array}$ & $\begin{array}{l}20(80 \%) \\
5(20 \%)\end{array}$ & $\begin{array}{l}9(69 \%) \\
4(31 \%)\end{array}$ & $\begin{array}{c}18(100 \%) \\
0(0 \%)\end{array}$ \\
\hline $\begin{array}{l}\text { UBT result on day } 21 \\
\text { (number, percent) }\end{array}$ & Positive & $5(100 \%)$ & $4(100 \%)$ & - \\
\hline
\end{tabular}




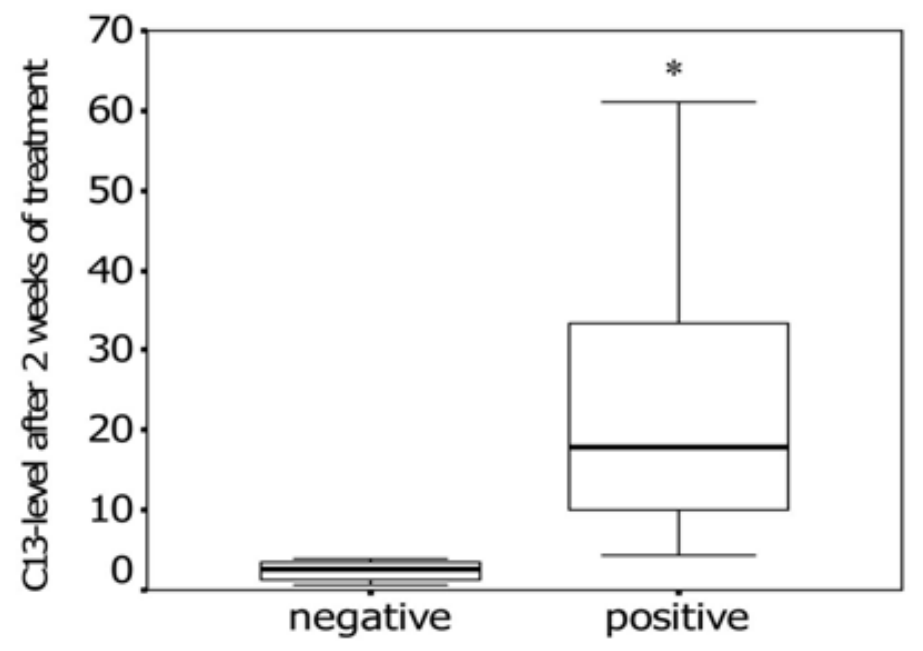

Fig. 1 The ${ }^{13} \mathrm{C}$ level two weeks after omeprazole intake in patients with negative/positive results. The bold line represents the mean ${ }^{13} \mathrm{C}$ level of group $\pm \mathrm{SEM}$ with the upper and lower border of the box corresponding to the maximal level and minimal level, respectively. ${ }^{*} \mathrm{p}=0.025$.

\section{Discussion}

The UBT was considered useful for initial diagnosis and for determining the success of H. pylori eradication [16]. In this study, patients in the omeprazole group were tested using ${ }^{13} \mathrm{C}$ UBT, while the other two groups used ${ }^{14} \mathrm{C}$ UBT due to the available of these tests. The accuracy of the UBT could be affected by numerous factors including PPIs usage. Consequently, cessation of PPIs 7-14 days before performing UBT is recommended. This is, however, a critical issue for patients dependent on medications due to severe symptoms. In the present study, we determined the false negative rate associated with various types of PPIs. Since rebamipide though our numbers are relatively small, statistical analysis would require a larger patient population.

The percentage of false negative results was $20.0 \%, 30.8 \%$, and $0 \%$ in the omeprazole, rabeprazole, and rebamipide group, respectively. A false negative rate caused by standard dose omeprazole differed among prior studies, ranging from $2.3 \%$ to $38.0 \%$ [7-11]. Levine A et al. [17] demonstrated that various types of PPIs had difference false negative rates (pantoprazole 2.2\%, omeprazole $4.1 \%$, esomeprazole $13.6 \%$ and lansoprazole $16.6 \%$ ). Similar results were also shown by Parente F et al. [10]. The reason for rabeprazole causing a high false negative rate could be explained by its potency and effect on H. pylori urease activity. Rabeprazole had faster onset of antisecretory action and higher potency than omeprazole compared on $1 \mathrm{mg}$ for $\mathrm{mg}$ basis [5]. In some studies, rabeprazole resulted in greater acid suppression than omeprazole [5-18]. In addition, growth inhibitory effect of rabeprazole over $H$. pylori was found to be more active than with omeprazole. As well, rabeprazole was about 10 times more potent than omeprazole in inhibiting urease at $\mathrm{pH} 5$ in both cellular and cell-free systems in vitro [6]. Therefore, higher potency of rabeprazole in urease inhibition could lead to higher false negative rates in UBT compared with omeprazole.

Rebamipide, a gastroprotective agent widely used in Japan, acts through the stimulation of prostaglandin and mucus glycoprotein synthesis, exhibiting inhibitory effect on reactive oxygen species and inflammatory cytokines [19-21]. In this study, we determined whether a mucoprotective agent, such as rebamipide, could adversely affect the accuracy of UBT. In accordance with the study by Murakami K et al. [22], no false negative results were obtained in the rebamipide group. They also found that treatment with rebamipide did not affect the post-treatment UBT $\Delta^{13} \mathrm{C} \%$ values. In the study by Adachi $\mathrm{K}$ et al. [23], no case gave a negative UBT result after rebamipide administration. Rebamipide did not affect the result of UBT, probably because it had no anti-secretory or anti-urease activity [24]. This positive effect of rebamipide might be beneficial in clinical practice. Since rebamipide might not have an effect on UBT, it could be used as an alternative drug for symptom relief in patients dependent on PPIs who have to stop medications before employing the UBT. 
All patients with false negatives gave positive results within two weeks after cessation of omeprazole or rabeprazole. Consequently, any patients scheduling for UBT were recommended not to take PPIs at least two weeks in advance to avoid false negative results. The time taken for the reversal of false negative results could depend on the time duration of prior PPIs usage. Accordingly, it might take longer in some patients for the test to be positive again.

In conclusion, omeprazole and rabeprazole adversely affected the accuracy of UBT, especially with rabeprazole, which had higher false negative rate. UBT did not seem to be influenced by the administration of rebamipide. It is recommended that PPIs usage should be prohibited for at least two weeks prior to UBT to avoid false negative results.

\section{Acknowledgement}

Rabeprazole $\left(\right.$ pariet $\left.^{\circledR}\right)$ and rebamipide $\left(\right.$ mucosta $\left.^{\circledR}\right)$ were provided by Eisai (Thailand) Marketing Co, Ltd and Thai Otsuka Pharmaceutical Co, Ltd, respectively. The authors have no conflict of interest to report.

\section{References}

1. Fennerty MB. Helicobacter pylori. Arch Intern Med. 1994; 254:721-7.

2. Marshall B. Helicobacter pylori. Am J Gastroenterol. 1994; 89:S116-28.

3. Colin WH, Richard HH. Guidelines for the management of Helicobacter pylori infection. Am J Gastroenterol. 1998; 93:2330-8.

4. Atherton JC. Non-endoscopic tests in the diagnosis of Helicobacter pylori infection. Aliment Pharmacol Ther. 1997; 11 (Suppl 1):11-20.

5. CAM Stedman, ML Barclay. Review article: comparison of the pharmacokinetics. Acid suppression and efficacy of proton pump inhibitors. Aliment Pharmacol Ther. 2000; 14:963-78.

6. John H. The proton pump inhibitors: similarities and differences. Clinical Therapeutics. 2000; 22:266-79.

7. Chey WD, Spybrook M, Carpenter S, Nostrant TT, Elta GH, Scheiman JM. Prolonged effect of omeprazole on the ${ }^{14} \mathrm{C}$-urea breath test. Am J Gastroenterol. 1996; 91:89-92.

8. Connor SJ, Seow F, Ngu MC, Katelaris PH. The effect of dosing with omeprazole on the accuracy of ${ }^{13} \mathrm{C}$-urea breath test in Helicobacter pylori-infected subjects. Aliment Pharmacol Ther. 1999; 13:1287-93.

9. Savirino V, Bisso G, Pivari M, Zentilin P, Bilardi C, Dulbecco P, et al. Effect of gastric acid suppression on
${ }^{13} \mathrm{C}$-urea breath test: comparison of ranitidine and omeprazole. Aliment Pharmacol Ther. 2000; 14:291-7.

10. Parente F, Sainaghi M, Sangaletti O, Imbesi V, Maconi G, Anderloni A et al. Different effects of short-term omeprazole, lansoprazole or pantoprazole on the accuracy of the ${ }^{13} \mathrm{C}$-urea breath test. Aliment Pharmacol Ther. 2002; 16:553-7.

11. Shirin H, Frenkel D, Shevah O, Levine A, Bruck R, Moss $\mathrm{S}$, et al. Effect of proton pump inhibitors on the continuous real time ${ }^{13} \mathrm{C}$-urea breath test. Am J Gastroenterol. 2003; 98:46-50.

12. Graham DY, Opekun AR, HammoudF, Yamaoka Y, Reddy $\mathrm{R}$, Osato MS, et al. Studies regarding the mechanism of false negative urea breath tests with proton pump inhibitors. Am J Gastroenteol. 2003; 98:1005-9.

13. Graham DY. An alternative explanation of the effect of citric acid on proton pump inhibitors-associated false negative urea breath tests. Am J Gastroenterol. 2001; 96:3032-9.

14. Klein PD, Malaty HM, Martin RF, Graham KS, Genta RM, Graham DY. et al. Noninvasive detection of Helicobacter pylori infection in clinical practice: the ${ }^{13} \mathrm{C}$ urea breath test. Am J Gastroenterol. 1996; 91: 690-4.

15. Desroches JJ, Lahaie RG, Picard M, Morais J, Dumont A, Gaudreau C, et al. Methodological validation and clinical usefulness of carbon-14 urea breath test for documentation of presence and eradication of Helicobacter pylori infection. J Nucl Med. 1997; 38: 1141-5.

16. Katelaris PH, Jone B. Testing for Helicobacter pylori infection after antibiotic treatment. Am J Gastroenterol. 1997; 92:1245-7.

17. Levine A, Shevah O, Shabat-Sehayek V, Aeed H, Boaz $\mathrm{M}$, Moss SF, et al. Masking of ${ }^{13} \mathrm{C}$-urea breath test by proton pump inhibitors is dependent on type of medication: compare between omeprazole, pantoprazole, lansoprazole and esomeprazole. Aliment Pharmacol Ther. 2004; 20:117-22.

18. Stack WA, Kniffon A, Thirlwell D, Cockayme A, Jenkins D, Hawkey CJ, et al. Safety and efficacy of rabeprazole in combination with four antibiotic regimens for the eradication of Helicobacter pylori in patients with chronic gastritis with or without peptic ulceration. Am J Gastroenterol. 1998; 93:1909-13.

19. Arakawa T, Kobayashi K, Yoshikawa T, Tarnawski A. Rebamipide: overview of its mechanism of action and efficacy in mucosal protection and ulcer healing. Dig Dis Sc. 1998; 43 (9 suppl):S5-13.

20. Sakurai K, Osaka T, Yamasaki K. Rebamipide induces 
recurrence of experimental gastric ulcers: role of free radicals and neutrophils. Dig Dis Sc. 2005; 50 (Suppl 1):S90-6.

21. Arakawa T, Higuchi K, Fujiwara Y, Watanabe T, Tominaga K, Sasaki E, et al. 15 th anniversary of rebamipide: looking ahead to new mechanism and new applications. Dig Dis Sc. 2005; 50 (Suppl 1):S3-11.

22. Murakami K, Sato R, Okimoto T, Watanabe K, Nasu $M$, Fujioka T, et al. Influence of anti-ulcer drugs used in Japan on the result of ${ }^{13} \mathrm{C}$-urea breath test for the diagnosis of Helicobacter pylori infection. J
Gastroenterol. 2003; 38:937-41.

23. Adachi K, Fujishiro H, Mihara T, komazawa $Y$, Kinoshita Y. Influence of lansoprazole, famotidine, roxatidine and rebamipide administration on the urea breath test for the diagnosis of Helicobacter pylori infection. J Gastroenterol Hepatol. 2003; 18:168-71.

24. Hayashi S, Sugiyama T, Amano K, Isogai E, Aihara M, Kikuchi M, et al. Effect of rebamipide, a novel antiulcer agent, on Helicobacter pylori adhesion to gastric epithelial cells. Antimicrob Agents Chemther. 1998; 42:1895-9. 